\title{
"Precisamos resistir, resistir! Eu preciso cantar": Terra em Transe e seu contexto histórico
}

Joabe França Mendonça

\section{Resumo}

Glauber Rocha se destacou no cenário cinematográfico participando do movimento Ginema Novo. Desde então, o cinema brasileiro produziu milhares de filmes, porém esse diretor continua chamando a atenção de espectadores e estudiosos de diversos campos. Foi a partir de experiências com o filme Terra em Transe, em pleno século XXI, que começamos a deslindar o papel que a produção ocupou em nossa história, em aspectos tanto políticos como estéticos e técnicos. Portanto, neste artigo, analisaremos o filme a partir de uma perspectiva histórica.

Palavras-chave: Glauber Rocha - Terra em Transe - História. 
Na última mostra "Retrospectiva: o Cinema Novo" apresentada na Cinemateca Brasileira, assistimos em coletividade aos filmes Terra em Transe (I967) e Maranhão 66, ${ }^{\mathrm{I}}$ ambos de Glauber Rocha. Poucas são as chances de assistir a obras desse diretor em uma tela de cinema. Praticamente todos os lugares estavam tomados pelo público, revelando assim a enorme curiosidade que o diretor ainda desperta, porém muitos espectadores se mostravam desconfortáveis ou entediados com a história que viam. Idas ao banheiro, inquietações nas poltronas ou ainda pequenas sonecas revelavam tal fenômeno. A partir de uma análise atenta de Terra em Transe e do contexto histórico de sua produção, podemos compreender os comportamentos daqueles espectadores em pleno século XXI.

As turbulências sociais, políticas e econômicas vistas no decorrer do governo de Jânio e João Goulart de certa forma ajudaram na formação de um grupo, o qual lançou a ideia de que, por meio da arte e da cultura, se poderia conscientizar os oprimidos e, por conseguinte, lançar uma revolução social. Vários nomes teciam esse círculo: Cacá Diegues, Nelson Pereira dos Santos, Glauber Rocha ${ }^{2}$ e outros. Com o golpe militar de I964, diversos artistas, como Glauber, perceberam que seus projetos (marcados como progressistas, democráticos, desenvolvimentistas e não paternalistas) não teriam como continuar. Como afirma Sanches (2000, p. 34):

[...] de início, as ideias de Glauber buscavam deseducação e reeducação simultâneas de um público acostumado a fórmulas prontas de cinema, com fins claramente políticos e estratégicos. Ora, se a democracia ruiu, se são os militares truculentos e não mais os burgueses progressistas que comandam o país, como levar adiante um projeto dessa natureza?

Por meio de um discurso autocrítico do fracasso e devido à própria emergência da censura dos anos I960, ${ }^{3}$ Terra em Transe desloca o espectador; o conforto

I Maranhão 66 é um documentário referente à posse de José Sarney daquele estado. Algumas cenas do documentário foram usadas em Terra em Transe (tal como tomadas aéreas dos eleitores), conferindo assim um tom de realidade à ficção. Tal artifício é comum em filmes que monumentalizam a história, já que traz veracidade. Ver NAPOLITANO, M. (Org.). História e cinema: dimensões históricas do audiovisual. São Paulo: Alameda Editorial, 2007.

2 Que "desde o início mostrou atípicos indícios de ser apto a ultrapassar dialeticamente a ingenuidade cega da esquerda e a cegueira cruel da direita". Ver SANCHES, Alexandre P. Tropicalismo: decadência bonita do samba. São Paulo: Boitempo, p. 33 .

3 É fulcral lembrarmos que a censura não se exerceu da mesma forma com os intelectuais e artistas, que não foram perseguidos como os militantes políticos até I968. Terra em Transe, apesar de suas duras 
proporcionado por filmes estadunidenses não é visto na obra de Glauber. Ao contrário, nele observamos múltiplas interpretações, uma fragmentação visual e narrativa e, consequentemente, uma pulverização do ponto de vista. Tudo isso acaba gerando uma franca angústia no espectador. A criação desse sentimento também se relacionava com o tipo de produções que abundavam no Brasil. Glauber afirma (2004, p. I28):

Se o filme, por ser nacional não é americano, decepciona. O espectador condicionado não aceita a imagem do Brasil vista por cineastas brasileiros porque ela não corresponde a um mundo tecnicamente desenvolvido e moralmente ideal como se vê nos filmes de Hollywood.

De forma semelhante, Xavier (2008, p. 202) faz uma análise do ritmo fílmico:

la texture du film est fait d'une accumulation d'élements, de répétitions obsédantes, d'une agitation incessante et d'un flux de paroles qui nous dépasse. Il y a un sentiment d'urgence sans répit, um ton exaspéré dans les leçons.

A desinformação de seu próprio país choca, e um produto como esse não é consumido. ${ }^{4}$ Portanto, surgiram questionamentos quanto ao caráter "nacional" de nosso cinema, mas como conquistar o público sem imitar formas exógenas? Para Glauber Rocha (2004, p. I30), "num país subdesenvolvido é fundamental que a sociedade adquira um comportamento nascido das condições de sua estrutura econômica”. O Ginema Novo, diferentemente do cinema de imitação, lança alguns desafios importantes, dentre eles o tipo de linguagem a ser utilizado. A recusa não se deu apenas à imitação do cinema estadunidense ou "europeu", mas igualmente ao "populismo" das artes nacionais. A ideia de que se deveria falar o simples, pois é isso que o povo entende, é altamente questionada: o povo é complexo. Como lembra Glauber (2004, p. I32), "o povo brasileiro critica sempre, de um ponto de vista conformista, sua própria miséria.

críticas à sociedade brasileira, foi exibido em circuito comercial, sendo mais criticado pelos próprios intelectuais de esquerda, seus pares, que não entenderam a crítica ali contida.

4 De acordo com Glauber (I963, p. 65 apud CALDAS, 2006, p. 9I), em um primeiro momento "o Cinema Novo marginaliza-se da indústria, porque o compromisso do Cinema Industrial é com a mentira e com a exploração”. Ulteriormente essa marginalidade foi repensada, e as necessidades e encantos do mercado foram considerados. A criação da Difilm (I965), por exemplo, sustenta-se também na ideia de que uma linguagem original só poderia ser praticada caso houvesse o controle do mercado. 
Na música popular são incontáveis os sambas que dizem 'não tendo feijão faço sopa de pedra', 'vou morrer na sarjeta, mas com muita alegria'”. Posteriormente, Glauber definiu como arte moderna aquela que é ética e revolucionária, que se opõe à dominação, e esse é um dos sentidos do Cinema Novo.

O embate entre público e Cinema Novo, por meio da perspectiva que delineamos, é duro e complexo, e mais: as mudanças se apresentavam como uma verdadeira revolução cultural; não apenas a estética era alterada, mas também os temas. Essa alteração não seria possível somente por meio de discursos. Luiz Carlos Barreto chamaria atenção do controle direto do mercado por meio das distribuidoras: a imposição de uma linguagem original só ocorreria concomitantemente com o controle do mercado. E somente por meio dessa "luta" seria possível acabar com o complexo de colonização cultural visto tanto nos espectadores como nos críticos.

Para intelectuais como Glauber Rocha, não interessava o que os "desenvolvidos" pensariam sobre nós, caso o preço fosse nos esquecermos de pensar sobre nossas próprias particularidades nacionais. O diretor via o "subdesenvolvimento" como uma força para o cinema nacional libertar-se da cultura de dominação (principalmente a estadunidense).

Terra em Transe é uma das produções que sobressai nesse cenário, tanto ideologicamente ${ }^{5}$ quanto esteticamente; podemos tomá-la como materialização do que discutimos até agora. Ambientado na República de Eldorado (espaço fictício), o filme conta com uma gama de personagens que incorporam períodos ou personagens da história da República. A seguir, mostraremos como, por meio de alegorias, a história do Brasil é "recontada", e como o diretor enxerga o devir nacional.

Um dos personagens centrais é Paulo Martins (Jardel Filho), um poeta que pode ser visto como o alter ego do diretor e revela um comunista típico - de acordo com Glauber -, ou seja, "um cara que vai à direita e à esquerda, que tem má consciência dos problemas políticos e sociais", "coloca-se a serviço do Partido quando este pressiona, mas gosta também muito da burguesia da qual ele está a serviço”. É também através dele que podemos notar uma crítica ao populismo e à estratégia da esquerda (principalmente do PCB). Paulo é caracterizado como uma figura de impulsos contraditórios e de reações histéricas, com um gestual extremamente teatralizado (XAVIER, I993, p. 49).

5 De acordo com Ismail Xavier (I999, p. 355), "the I96os and early I970s were a time of intense political debate, and film production became politicized as never before. The ideological atmosphere favored global critiques and a 'state of the nation 'discourse". 
Em contraposição a essa esquerda, temos o político em ascendência, Porfirio $\operatorname{Diaz}^{6}$ (Paulo Autran), que representa não apenas as forças que estão no poder, mas também o conservadorismo que chegou ao Brasil Colonial e aqui permaneceu. Segundo Xavier (I993, p. 54), Diaz é "como a condensação da elite mais tradicionalista, sua palavra de ordem é a pureza, o direito natural, a dominação como apanágio da aristocracia”. Essa é uma das principais alegorias no filme. Uma das cenas clássicas é a coroação de Diaz (a partir de Ih4Imin), que simboliza o golpe de estado. O ator aparece em "close-up" balburdiando palavras (porém sua fala não é escutada pelo espectador) num espaço determinado: o palácio barroco, que pode ser visto como a violência colonial europeia no Brasil. Ulteriormente, Paulo morre (assim como o seu sonho), e Diaz agora é facilmente ouvido: "Aprenderão, aprenderão. Dominarei essa terra. Botarei essas histéricas tradições em ordem, pela força, pelo amor da força, pela harmonia universal dos infernos e chegaremos a uma civilização" (TERRA..., I967). Xavier (I993, p. 35), analisando a mesma cena, vê nesse momento que "é chegada a hora [de Diaz] engolir os seus inimigos".

Já Vieira (José Lewgoy), em primeiro momento, representa um suposto progressista, todavia acaba se mostrando fraco frente às forças políticas e econômicas que o financiaram em sua campanha para governador. Para Sanches (2000, p. 37):

Vieira metaforiza o líder pré-revolucionário que Goulart pretendia ser, na rota da esquerda rumo à revolução, à vitória política. Vieira se aproxima definitivamente de Jango na incapacidade de resistir a contra-revolução.

$\mathrm{Na}$ trama, Paulo demonstra sua "incoerência" ao transitar entre as personagens políticas supracitadas e a isso se soma a relação do poeta com o povo: em alguns momentos, apresenta uma visão positiva, enquanto em outros o povo tem de ser calado e apenas conduzido. A crítica é clara: a esquerda não tem um projeto claro e racional.

Outras críticas glauberianas podem ser vistas em "personagens secundárias", como a Igreja, que sempre está do lado de quem tem o poder. Júlio Fuentes (Paulo Gracindo) representa o capital nacional, mas verbaliza fazer apenas o bem para o país (ainda aparece ao lado de Diaz em sua coroação).

6 O próprio nome do personagem remete ao conservadorismo histórico. No contexto brasileiro, uma aproximação razoável seria com o antigetulista Carlos Lacerda. Em vias opostas, Vieira seria também o líder gaúcho Leonel Brizola (caudilho e populista). 
Além do mais, é um pilar da dominação por meio do dinheiro. Em nossa análise, Sara (Glauce Rocha) - com destaque menor na obra -, que retrata uma militante comunista, é a exemplificação da coerência, traço que certamente está ausente nas outras personagens de Terra em Transe, assim como na sociedade brasileira. Além da multiplicidade simbólica que o filme carrega, esteticamente a produção acaba se chocando com o "padrão estadunidense hegemônico", ilustrando a complexificação vista no Cinema Novo. ${ }^{7}$ Constatamos em Glauber uma inspiração brechtiana: meios como a duplicação de cenas, o embaralhamento temporal ${ }^{8}$ e a busca do estranhamento são recursos lançados pelo diretor. Somam-se a isso os cenários barrocos. De acordo com Xavier (2008, p. 203),

cette iconographie montre le présent comme la répétition d'une violance du passe, Diaz étant l'héritier de l'entrepise colonial européenne, dans as domination des autres cultures sous les tropiques. Son rôle est de reproduire cette violence.

Tecnicamente, o filme é marcado por algumas singularidades, dentre elas a gravação com a câmera na mão: a movimentação do diretor com a filmadora cria um laço entre ele e os atores. No prenúncio da morte de Paulo Martins (a partir de 12 mino5s), os planos são marcados pela grande movimentação da câmera que se conecta com diálogos nervosos sobre o golpe de Estado contra Vieira. Posteriormente, temos o prenúncio da morte do poeta, concretizando a tensão criada pela "câmera nervosa". Araújo (2006, p. 92) reproduz parte da entrevista de Glauber que revela o uso dessa técnica:

O filme foi frequentemente filmado com a câmera na mão, de modo flexível. Sente-se a pele dos personagens, procurei um tom documentário. Tudo que pode parecer imaginário é de fato verdadeiro. Fui, por exemplo, consultar arquivos de jornais para ver fotografias de políticos. Quando o Presidente Kubits-

7 Vale ressaltar que Glauber usou amplamente alegorias em seus filmes. lsmail Xavier (I999) afirma que "the I964 military coup d'état placed the leftist filmmakers in a difficult position, obliging them to perform historical revisions and a kind of autocritical recapitulation of the recent past which found its best translation in the baroque drama of disenchantment made by Rocha in I967, Land in Anguish". As alegorias podem ser explicadas a partir tanto da censura (que o filme poderia sofrer) quanto das inclinações de Glauber em forjar uma síntese, produzir uma visão condensada e totalizante da história nacional.

8 A fragmentação da narrativa também foi um recurso amplamente usado em movimentos como o Tropicalismo. 
chek chega a Brasília, por exemplo, os índios lhe levam um cocar de cacique, etc. Quando filmei o comício onde o velho senador começa a dançar com as pessoas, mandei vir uma verdadeira escola de samba e botei Vieira no meio.

Diante de tudo o que discutimos, concluímos que Terra em Transe é um rico documento não apenas para analisar a história e evolução do cinema brasileiro, mas também para compreender a vida política do país. Paulo afirma: "precisamos resistir, resistir! Eu preciso cantar". No último longo plano (de quase um minuto), ao som de metralhadoras que nos perturbam, percebemos uma alusão à luta armada: os planos da esquerda tinham falhado. ${ }^{9} \mathrm{O}$ filme de Glauber é um símbolo de resistência, seja política (frente ao golpismo) seja técnica/estética (frente aos desejos da indústria com "padrões comerciais"). Xavier (I993, p. 65) afirma: "observá-la [a obra Terra em Transe] hoje é se deparar com a representação implacável do jogo de poder capaz de expor um quadro da cultura política brasileira que ultrapassa em muito aquela conjuntura específica”.

\section{Referências}

ARAÚJO, Régis Frota. Terra em transe. São Paulo: ABG Editora, 2006.

CALDAS, Ricardo W.; MONTORO, Tânia. A evolução do cinema brasileiro no século XX. Brasília: Casa das Musas, 2006.

NAPOLITANO, Marcos. "Monumentalização e escrita fílmica da história: uma comparação entre Danton e Amistad”. In: MORETTIN, Eduardo et al. (Orgs.). História e cinema: dimensões históricas do audiovisual. São Paulo: Alameda Editorial, 2007.

ROCHA, Glauber. Revolução do Cinema Novo. São Paulo: Cosac Naify, 2004.

SANCHES, Pedro Alexandre. "Terra em transe" e "Panis et circensis". In:

Tropicalismo: decadência bonita do samba. São Paulo: Boitempo, 2000. p. 29-79.

TERRA em transe. Direção: Gláuber Rocha. Rio de Janeiro: Mapa Produções Cinematográficas, I967 [produção]. I filme (IO5 min), 35 mm, p\&b. Cópia da Cinemateca Brasileira.

9 O uso de um poema de Mário Faustino é uma clara alusão à derrota da esquerda e de Paulo no filme: "Não conseguiu firmar o nobre pacto/Entre os cosmos sangrento e alma pura [...] Gladiador defunto mas intacto/Quanta violência mas quanta ternura". Ver Xavier (I993, p. 35). 
"Precisamos resistir, resistir! Eu preciso cantar": Terra em Transe e seu contexto histórico

XAVIER, Ismail Norberto. Historical Allegories. In: MILLER, Toby; STAM, Robert (Orgs.). A companion to film theory. Oxford: Blackwell Publishers, I999. p. 333-362.

- Glauber Rocha et l'esthetique de la faim. Paris: L'Harmattan, 2008.

Alegorias do subdesenvolvimento. São Paulo: Editora Brasiliense, I993.

Joabe França Mendonça é graduando em História pela Universidade de São Paulo.

joabe.mendonca@usp.br 